\title{
Article \\ Polyphasic OKJIP Chlorophyll $a$ Fluorescence Transient in a Landrace and a Commercial Cultivar of Sweet Pepper (Capsicum annuum, L.) under Long-Term Salt Stress
}

\author{
Pasquale Giorio *(D) and Mohamed Houssemeddine Sellami $\mathbb{D}$ \\ National Research Council of Italy, Institute for Mediterranean Agricultural and Forestry \\ Systems (CNR-ISAFOM), Piazzale Enrico Fermi, 1 Località Porto del Granatello, 80055 Portici, NA, Italy; \\ hsellemi@yahoo.fr \\ * Correspondence: pasquale.giorio@cnr.it
}

Citation: Giorio, P.; Sellami, M.H. Polyphasic OKJIP Chlorophyll $a$ Fluorescence Transient in a Landrace and a Commercial Cultivar of Sweet Pepper (Capsicum annuum, L.) under Long-Term Salt Stress. Plants 2021, 10, 887. https://doi.org/10.3390/ plants10050887

Academic Editor: Michael Moustakas

Received: 27 March 2021

Accepted: 25 April 2021

Published: 28 April 2021

Publisher's Note: MDPI stays neutral with regard to jurisdictional claims in published maps and institutional affiliations.

Copyright: (C) 2021 by the authors. Licensee MDPI, Basel, Switzerland. This article is an open access article distributed under the terms and conditions of the Creative Commons Attribution (CC BY) license (https:// creativecommons.org/licenses/by/ $4.0 /)$.

\begin{abstract}
In a soilless long-term salt-stress experiment, we tested the differences between the commercial sweet pepper cultivar "Quadrato d'Asti" and the landrace "Cazzone Giallo" in the structure and function of PSII through the JIP test analysis of the fast chlorophyll fluorescence transients (OKJIP). Salt stress inactivated the oxygen-evolving complex. Performance index detected the stress earlier than the maximum quantum yield of PSII, which remarkably decreased in the long term. The detrimental effects of salinity on the oxygen evolving-complex, the trapping of light energy in PSII, and delivering in the electron transport chain occurred earlier and more in the landrace than the cultivar. Performance indexes decreased earlier than the maximum quantum yield of PSII. Stressinduced inactivation of PSII reaction centers reached $22 \%$ in the cultivar and $45 \%$ in the landrace. The resulted heat dissipation had the trade-off of a correspondent reduced energy flow per sample leaf area, thus an impaired potential carbon fixation. These results corroborate the reported higher tolerance to salt stress of the commercial cultivar than the landrace in terms of yield. PSII was more affected than PSI, which functionality recovered in the late of trial, especially in the cultivar, possibly due to heat dissipation mechanisms. This study gives valuable information for breeding programs aiming to improve tolerance in salt stress sensitive sweet pepper genotypes.
\end{abstract}

Keywords: JIP test; Kautsky effect; photosynthesis; PSII photosystem; salinity; stress tolerance

\section{Introduction}

The world population will exceed 9 billion in 2050 [1] when $50 \%$ of croplands may not produce food because of soil salinization [2]. Local ecotypes or landraces have stable though moderate yield capacity and potentially high-stress tolerance [3]. Thus, they represent valuable genetic reservoirs of genes underlying stress tolerance. Uncovering the differences in the physiological responses to stress between species or among landraces and cultivars is a premise for planning successful breeding programs for stress-tolerant commercial cultivars [4,5]. Plant roots must exclude most of the $\mathrm{Na}^{+}$and $\mathrm{Cl}^{-}$of the soil solution to avoid salts quickly reach lethal levels in the shoots. Compartmentalization of the retained tiny portion of saline ions in the cell vacuoles and the balancing osmotic pressure of organic solutes in the cytosol assures the required osmotic adjustment to match soil solution [6]. In the short-term, salinity causes osmotic stress in the root-zone, which triggers ABA-mediated stomatal closure that limits photosynthesis [7]. In the long-term, the accumulation of salts in the leaves causes ionic toxicity and ionic imbalances, with disruption of ion homeostasis and oxidative stress [8]. Thus, photosynthesis is further impaired by metabolic limitations [9].

Analysis of the fast fluorescence induction is a reliable and quick non-destructive tool to investigate the photosynthetic apparatus's structure and function in response to various types of stress [10]. PSII reaction centers (RCs) are open in dark-adapted leaves, as all the 
stable primary PSII acceptor $\mathrm{Q}_{\mathrm{A}}$ molecules are oxidized. There is neither water oxidation by PSII nor energy flow in the electron transport chain, and $\mathrm{Chl} a$ fluorescence emission $\left(\mathrm{F}_{\mathrm{t}}\right)$ is at basal level $\left(\mathrm{F}_{\mathrm{o}}\right)$. Upon exposure to actinic light, $\mathrm{F}_{\mathrm{t}}$ shows a polyphasic fast rise (Kautsky effect), with significant steps between the basal level and the peak value, $\mathrm{F}_{\mathrm{P}}$ (OJIP curve) [11]. During the photochemical phase (O-J), $\mathrm{F}_{t}$ rises from $\mathrm{F}_{\mathrm{o}}$ (point $\mathrm{O}$ ) to $\mathrm{F}_{\mathrm{J}}$ after $2 \mathrm{~ms}$ (point J), which indicates the single turnover reduction of $Q_{A}$ [12]. During the subsequent much slower thermal phase (J-I), the rise from $\mathrm{F}_{\mathrm{J}}$ to $\mathrm{F}_{\mathrm{I}}$ at $30 \mathrm{~ms}$ is due to the reduction of the secondary quinone acceptor $\mathrm{Q}_{\mathrm{B}}$, the $\mathrm{PQ}$ pool, and the cytochrome $\mathrm{b}_{6} \mathrm{f}$ complex. At the end of this phase (point I), electrons reach plastocyanin and then ferredoxin at the PSIs electron acceptor side. Their reduction continues in the next slowest thermal phase (I-P) as $F_{t}$ rises to the peak value $\left(F_{P}\right.$, point $\left.P\right)$ in less than $1 \mathrm{~s}$. Under saturating illumination, $F_{P}$ represents the maximum emission $\left(\mathrm{F}_{\mathrm{M}}\right)$, which indicates the reduction of all $\mathrm{Q}_{\mathrm{A}}$ molecules and the saturation of electron flow at the acceptor side of PSII. Thus, all RCs are considered closed [11]. Other significant steps can show up in the polyphasic rise, such as the K step at $0.30 \mathrm{~ms}$ (point $\mathrm{V}_{\mathrm{K}}$ ) (OKJIP curve). Inhibition of the water-splitting system increases $\mathrm{V}_{\mathrm{K}}$; thus, analysis of Kautsky curves allows investigation of the donor side of PSII [13,14].

In the late seventies, Prof. Reto J. Strasser conceived the theory of energy fluxes in the thylakoid membranes [15] and developed the related Kautsky curve JIP test analysis. The test provides several parameters related to the structure and function of photosystems [12,15], namely PSII and its relationships with PSI functioning [16]. Detailed definitions and equations of raw and derived JIP test fluorescence parameters are reported in Table 1 (see also [11]). Authors have used JIP test to study the effects of various types of stress [17] Faseela at al.2020 [18], such as heat [13,19] drought [20-23], salinity [24,25], combined drought and salt stress [26,27] ozone [28,29], nutrient deficiency [30,31], toxic metals [10], or climate change [32].

Sweet pepper (Capsicum annuum, L.) is an essential horticultural crop in the world as it is in Italy [33]. Pepper grown in either open field or greenhouse is moderately sensitive to salinity [34]. Higher yield and better fruit quality are obtained in glasshouse than open field conditions [35]. In a soilless culture, the response of sweet pepper marketable fruits to the electrical conductivity $\left(\mathrm{EC}_{\mathrm{w}}\right)$ of the nutrient solution had a threshold of $2.8 \mathrm{dS} \mathrm{m}^{-1}$ and a slope of 7.6\% [36]. This species shows some salt tolerance differences among cultivars [37-39]. In a long-term salt-stress experiment, [40] Giorio et al. (2020) tested the hypothesis of higher salt stress tolerance of a traditional landrace than a widely spread high-yield commercial cultivar. Nevertheless, the commercial cultivar showed better salt tolerance than the landrace in terms of yield reduction. The accumulation of sodium in the stems was lower in the commercial cultivar than in the landrace. The authors argued that the higher chloride exclusion from leaves permitted more extended photosynthetic apparatus functionality in the commercial cultivar than in the landrace. On this basis and for the same experiment, in this work, we have verified the hypothesis of significant differences between the two sweet pepper genotypes in the structure and function of the photosystems, namely, PSII, assessed through the JIP test analysis of the Chl $a$ fluorescence induction transients (OKJIP curves).

Here, we demonstrated that long-term salt stress caused loss of efficiency in the oxygen-evolving complex (OEC) and along the path from light absorption, trapping of excitation energy, and electron transport between PSII and PSI acceptors. These effects occurred earlier and at a greater extent in the landrace than the commercial cultivar. Due to the higher inactivation of PSII reaction centers, the landrace had lower electron transport per sampled leaf area and thus lower $\mathrm{CO}_{2}$ fixation capacity than the commercial cultivar. These results corroborate the reported explanation for the difference in the salt-stress tolerance of yield between the two sweet pepper genotypes and confirm the high usefulness of JIP test analysis of polyphasic fluorescence transients to screen for stress tolerance. 
Table 1. Nomenclature and formulae of the OKJIP transient and related JIP test parameters (modified after [11]).

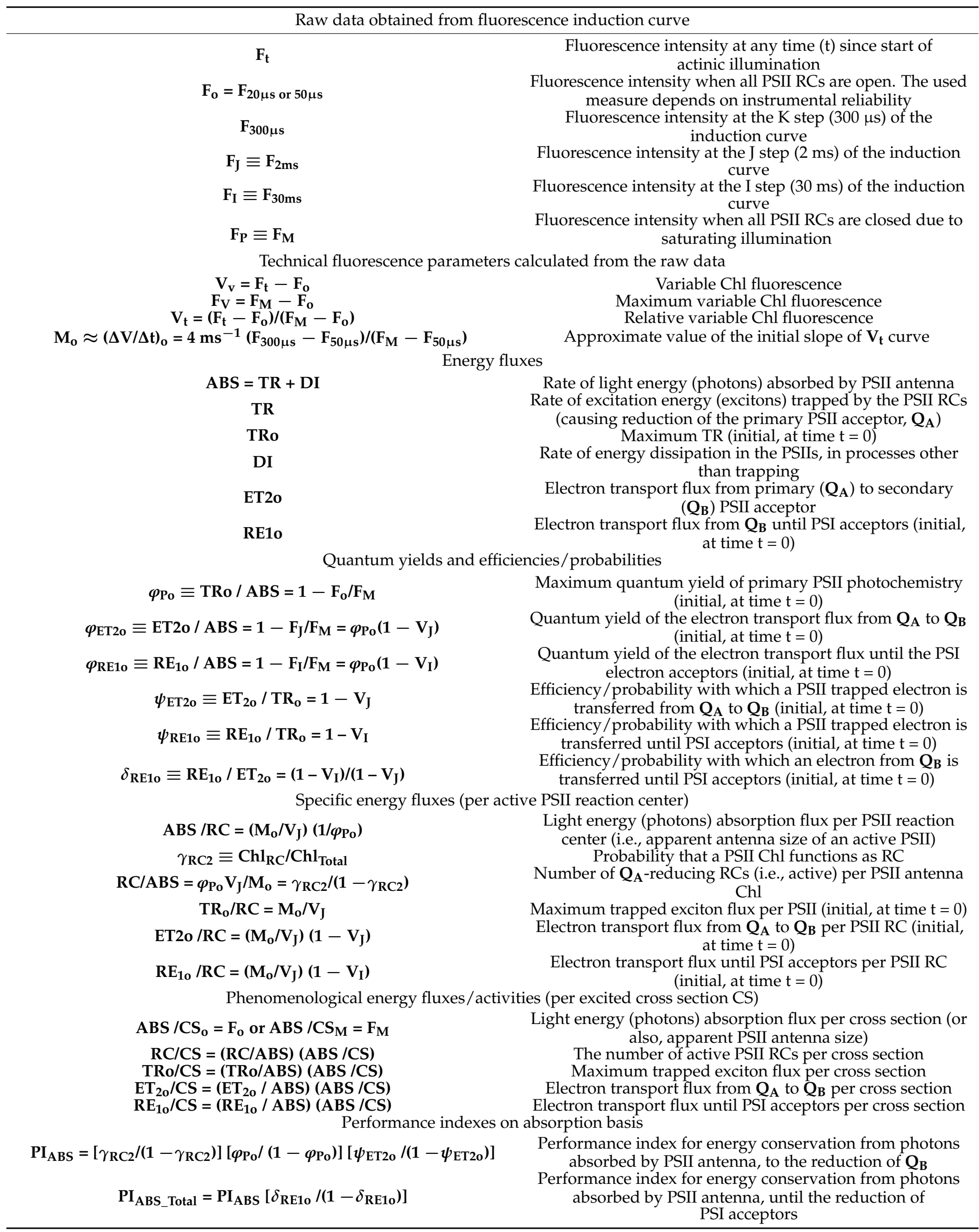




\section{Results and Discussion}

Glycophytic species growing in salinized soils struggle with stress conditions along all their life cycle. Therefore, long-term experiments are required to uncover differences in stress tolerance mechanisms between species or cultivars and landraces. Two sweet pepper genotypes, the landrace "Cazzone Giallo" (CG) and the commercial cultivar "Quadrato d'Asti" (QA), were grown with a nutrient solution (NS) (control treatment, S0) or with NS added by 120 mmol liter ${ }^{-1} \mathrm{NaCl}$ from 13 days after transplanting (DAT 13) until harvest (DAT 168) (salt treatment, S120). We investigated the function and structure of photosynthetic apparatus through the JIP test analysis of OKJIP curves in response to long-term exposure to salinity.

\subsection{OKJIP Polyphasic Fluorescence Transients}

Stress conditions impair photosynthesis and rouse mechanisms to dissipate excitation energy excess as heat and fluorescence [41]. A tiny portion of the light absorbed by photosystem PSII is re-emitted as Chl $a$ fluorescence. However, it is strictly related to the structure and function of photosynthetic apparatus [11]. Double normalization of $F_{t}$ produced the OKJIP curves of $V_{t}$. The $V_{t}$ curves were plotted on a logarithmic time scale to display the physiologically significant steps [42,43] (Figure 1). Assuming no connectivity between PSII units, $V_{t}$ equals the fraction of closed PSII reaction centers $\left(\left[\mathrm{Q}_{\mathrm{A}}{ }^{-}\right] /\left[\mathrm{Q}_{\mathrm{ATotal}}\right]\right)$. This ratio drives the kinetics of $\mathrm{Chl} a$ fluorescence induction, and it is affected directly or indirectly by the rate of all photosynthetic reactions up- and downstream the oxydoreduction of $\mathrm{Q}_{\mathrm{A}}[11,44,45]$.

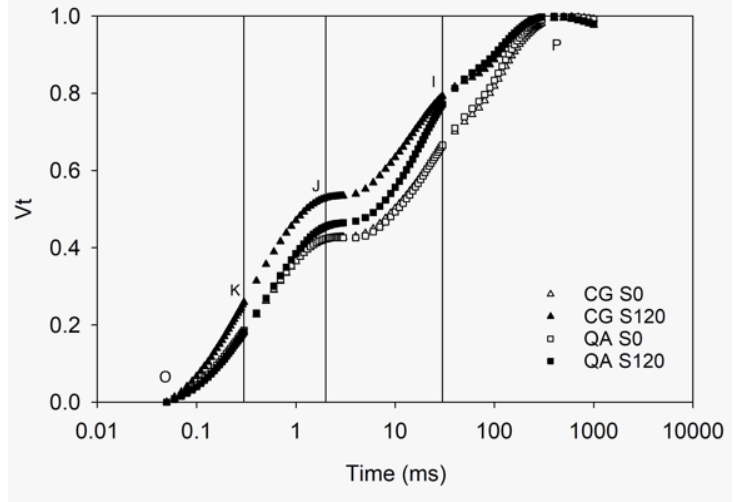

(a)

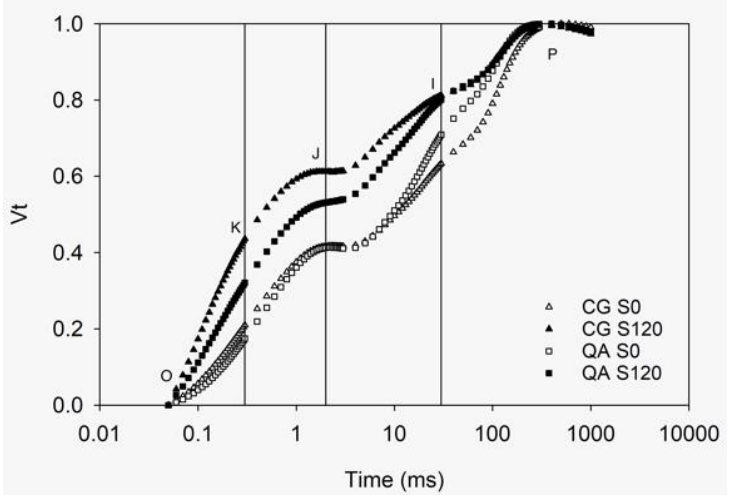

(b)

Figure 1. Polyphasic rise of relative variable fluorescence $\left(\mathrm{V}_{\mathrm{t}}\right)$ upon illumination with saturating light of dark-adapted leaves of cultivar QA and landrace CG for treatments S0 and S120 measured on DAT 82 (a) and DAT167 (b). In each panel, the vertical lines intersect the K point at $300 \mu \mathrm{s}$ (left line), the J point at $2 \mathrm{~ms}$ (middle line), and then I point at $30 \mathrm{~ms}$ (right line). Values are the means of 24 replicates.

On DAT 82 (Figure 1a), the polyphasic rise of $V_{t}$ was higher in S120 than in control plants, especially in CG, and the differences increased afterward (data not shown). On DAT 167 (Figure $1 b), V_{K}$ (K step) was higher in CG than QA of treatment S120 and higher in S120 than S0 of both genotypes, which implied lower efficiency of the donor side of PSII [14]. Similarly, higher $\mathrm{V}_{\mathrm{J}}$ (J step) reflected a higher accumulation of reduced primary PSII acceptor $\mathrm{Q}_{\mathrm{A}}{ }^{-}$, thus lower efficiency of the electron transport from $\mathrm{Q}_{\mathrm{A}}$ to $\mathrm{Q}_{\mathrm{B}}\left(\psi_{\mathrm{ET2O}}\right)$ [11]. A reduced I-P phase in S120 compared to S0 denoted loss of efficiency of electron flow from primary acceptor $Q_{A}$ until PSI electron acceptors $\left(\psi_{\text {RE1o }}\right)$ [16] (Table 1$)$. Data of $F_{t}$ at the points $\mathrm{O}, \mathrm{K}, \mathrm{J}$, I and $p$ are shown in Figure S1. 


\subsection{Donor Side of PSII}

The oxygen-evolving complex $(\mathrm{OEC})$ is one of the most stress-sensitive photosynthetic components [10] and the most sensitive to heat stress [46]. Although not often evident, the $\mathrm{K}$ step is considered a natural and always present phenomenon, elicited by any inhibition of the water-splitting system [47]. High salt stress in wheat affected the donor side of PSII more than the acceptor side [48]. OEC inactivation induces an increase in $V_{K}$, a typical feature of heat-stressed leaves [13,47]. K step is often hidden in leaves under weak heat stress or other types of stress. Nonetheless, the increase of $V_{K} / V_{J}$, also known as $W_{K}$, revealed OEC inactivation [19]. For instance, it was observed under water stress [20], salt stress [18,25], low-nitrogen fertilization [31], or during leaf senescence [49]. Along the experiment, the increase occurred in $\mathrm{S} 120$ plants (Figure $2 \mathrm{a}$ ), while as expected, $\mathrm{V}_{\mathrm{K}} / \mathrm{V}_{\mathrm{J}}$ remained proximal to 0.5 in the control plants [19]. Incomplete water splitting with consequent reduction of the electron supply to the reaction centers of PSII leads to an excess of excitation energy and ROS generation, which causes oxidative damage to thylakoid membranes $[41,50]$. High levels of ROS are quite deleterious to growth and crop yield if there is insufficient scavenging by the enzymatic and the non-enzymatic antioxidants [51]. Drought tolerant cultivars showed more pronounced K step than the less tolerant ones [20]. The authors proposed $\mathrm{K}$ step as a potential early stress indicator before the occurrence of any visible symptom. Inhibition of OEC occurred more and earlier in CG than in QA (Figure 2a).

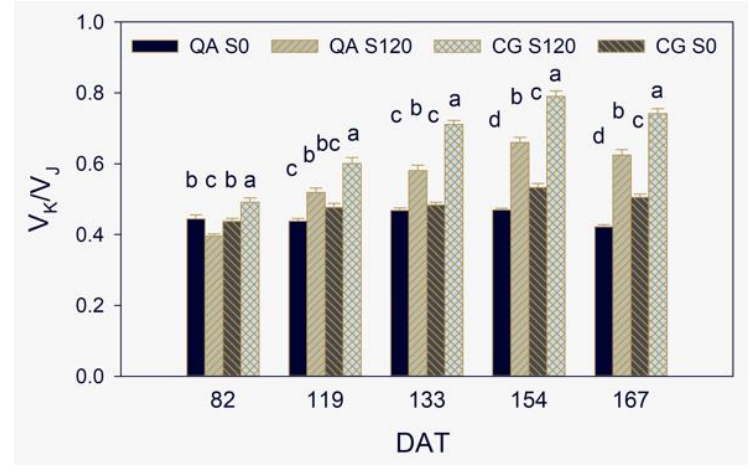

(a)

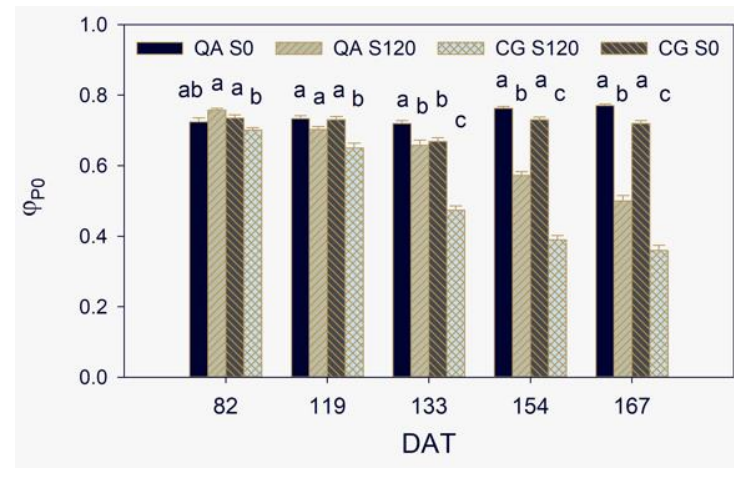

(b)

Figure 2. The ratio of $\mathrm{V}_{\mathrm{K}}$ to $\mathrm{V}_{\mathrm{J}}(\mathbf{a})$ and the maximum quantum yield of primary PSII photochemistry, $\varphi_{\text {Po }}(\mathbf{b})$ from DAT 82 to DAT 167. Values are the means of 24 replicates. The vertical line on each bar represents the standard error of the mean. Within each DAT, values among the four $\mathrm{G} \times \mathrm{S}$ combinations with the same letter are not significantly different at $p<0.05$.

\subsection{Maximum Quantum Yield, Efficiencies of Electron Transport, and Performance Indexes}

After more than two months since starting salinity treatment (DAT 82), the maximum quantum yield of PSII, $\varphi_{\mathrm{Po}}$, showed low sensitivity to salt stress (Figure 2b). In S120 of $\mathrm{CG}, \varphi_{\text {Po }}$ was only $5 \%$ lower than the other three $\mathrm{G} \times \mathrm{S}$ combinations, which values were proximal to the optimum 0.83 [52]. It is common to observe little response of $\varphi_{\mathrm{Po}}$ to various types of stress as reported for salinity in wheat [48], drought in barley [20], and salinity or drought in sunflower [27]. Since DAT 154, $\varphi_{\mathrm{Po}}$ in $\mathrm{S} 120$ was statistically significantly lower than S0 in both QA and CG.

The energy-dependent (qE), the state transition (qT), and the zeaxanthin-dependent (qZ) quenching mechanisms dissipate excitation energy excess as heat. They occur within seconds to tens of minutes or up to more than an hour and prevent potential photodamage to photosynthetic apparatus [53]. More precisely, the less the thermal dissipation, the more the photodamage [54]. Under sustained stress conditions, as it was for S120 treatment that showed low $\mathrm{CO}_{2}$ assimilation since DAT 102 [40], these mechanisms may result insufficient. Further investigations are required to quantify NPQ mechanisms to confirm this assertion in the two pepper genotypes under our experimental conditions. Excess of excitation 
energy leads to permanent/slow-reversible reduction of electron acceptors, leakage of electrons, and generation of harmful reactive radicals [41]. To avoid photodamages under high light, plants have also developed photoinhibitory quenching mechanisms (qI). They involve inactivation and degradation of D1 protein in the PSII reaction centers that take hours or longer to turn on and off [53]. The trade-off of these mechanisms is photoinhibition, a light-induced decrease of the quantum yield of photosynthetic $\mathrm{CO}_{2}$ assimilation. After DAT 82, $\varphi_{\text {Po }}$ decreased in S120 plants of both the two genotypes and at DAT 167 reached the remarkable low values of 0.50 in QA and 0.36 in CG, which indicated a pronounced photoinhibition [52,55]. A similar decrease in $\varphi_{\text {Po }}$ measured at midday suggested a marked photoinhibition with associated high energy dissipation in perennial ryegrass under stressful climatic conditions [56]. Alike $\mathrm{V}_{\mathrm{K}} / \mathrm{V}_{\mathrm{J}}$, salinity affected $\varphi_{\text {Po }}$ earlier and to a greater extent CG than QA (Figure $2 b$ ).

Strasser et al. $[15,57]$ introduced the performance index on absorption basis $\mathrm{PI}_{\mathrm{ABS}}$ that integrates three independent Nernst-type parameters (Table 1), which in chemistry express the ratio between the reduced and the oxidized concentration of a compound [11,24] and references therein. Thus, $\mathrm{PI}_{\mathrm{ABS}}$ refers to the energy conservation in the path from light energy absorption, excitation energy trapping, and delivery in the intersystem electron transport chain. As $\gamma$ is the probability for a Chl molecule to function as a reaction center, the structure component parameter $\gamma_{\mathrm{RC} 2} /\left(1-\gamma_{\mathrm{RC} 2}\right)=\mathrm{RC} / \mathrm{ABS}$ is the number of active RC per PSII antenna Chl. The component $\varphi_{\mathrm{Po}} /\left(1-\varphi_{\mathrm{Po}}\right)$ here measured as $\mathrm{F}_{\mathrm{V}} / \mathrm{F}_{\mathrm{o}}$ refers to the partial performance of primary photochemistry as it represents the ratio between trapped and dissipation energy fluxes TRo/DIo. The component $\psi_{\mathrm{ET} 2 \mathrm{o}} /\left(1-\psi_{\mathrm{ET} 2 \mathrm{O}}\right)$ is for the performance of thermal reactions of the intersystem electron carriers as $\psi_{\mathrm{ET} 2 \mathrm{O}}=\mathrm{ET}_{2 \mathrm{o}} / \mathrm{TR}_{\mathrm{o}}$ is the efficiency/probability with which an electron trapped in $Q_{A}$ is transferred to $Q_{B}$ (Table 1). To include the photosynthetic performance of electron transport beyond $Q_{B}$, $\mathrm{PI}_{\mathrm{ABS}}$ was extended to $\mathrm{PI}_{\mathrm{ABS} \_ \text {Total }}$ [58], which incorporates a fourth component based on $\delta_{\mathrm{RE1} 1}$, the efficiency/probability with which an electron is transferred from $\mathrm{Q}_{\mathrm{B}}$ to PSI electron acceptors [11].

In contrast to $\varphi_{\mathrm{Po}}$, many papers have reported a rapid decrease of $\mathrm{PI}_{\mathrm{ABS}}$ in response to various types of stress, such as water deficit $[18,20,21,59]$, salinity $[25,48]$, and a decrease of $\mathrm{PI}_{\mathrm{ABS} \_ \text {Total }}$ as reported for moderate ozone stress [29]. Even during a daily cycle in a grass species, $\mathrm{PI}_{\mathrm{ABS}}$ significantly decreased before $\varphi_{\mathrm{Po}}$ on a more than a less stressful day during summer [56]. The two PIs were significantly lower in S120 than S0 in both the two genotypes since DAT 82 and reached at DAT 167 insubstantial tiny values due to the severe stress conditions (Figure $3 \mathrm{a}, \mathrm{b}$ ). Alike both $\mathrm{V}_{\mathrm{K}} / \mathrm{V}_{\mathrm{J}}$ and $\varphi_{\mathrm{Po}}$, the salinity effect on PIs along the trial was stronger in CG than QA, which further indicated lesser salt stress tolerance of the former than the latter genotype.

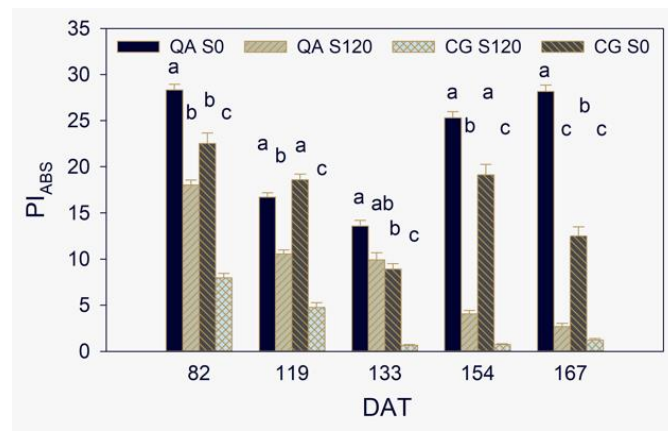

(a)

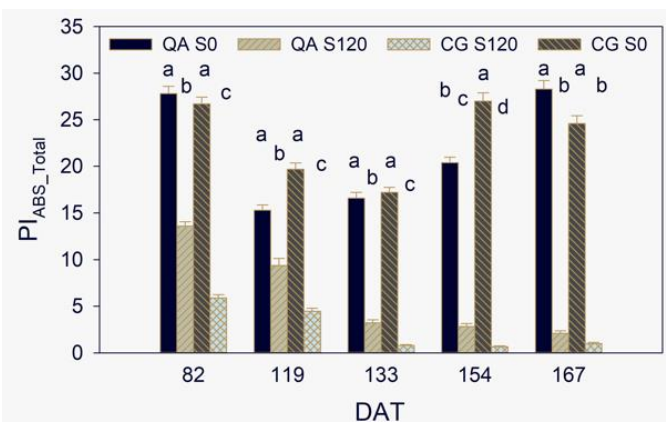

(b)

Figure 3. The two performance indexes on absorption basis, $\mathrm{PI}_{\mathrm{ABS}}(\mathbf{a})$ and $\mathrm{PI}_{\mathrm{ABS} \_ \text {total }}(\mathbf{b})$, from DAT 82 to DAT 167. Values are the means of 24 replicates. The vertical line on each bar represents the mean standard error. Within each DAT, values among the four $\mathrm{G} \times \mathrm{S}$ combinations with the same letter are not significantly different at $p<0.05$. 
The effect of salinity on the PIs components expressed as S120 normalized by S0 (S120/S0) is shown as spider plots in Figure 4. Thus, the lower the normalized value, the higher the salt stress effect in S120, while the normalized parameters equal unit in S0. During the experiment, the decrease of the normalized RC/ABS observed in both genotypes, if not due to an enlargement in the antenna size, can be attributed to the stressinduced conversion of the reaction centers from active $(R C)$ to non- $Q_{A}$ reducing reaction centers, called inactive or silent $\left(\mathrm{RC}_{\text {silent }}\right)$ [15]. On DAT 82, the deleterious effect of salt stress on the conservation energy increased (i.e., the normalized parameters decreased), along the path from the trapping of excitation energy in PSII expressed by the normalized component $\left[\varphi_{\mathrm{Po}} /\left(1-\varphi_{\mathrm{Po}}\right)\right]$, to electron transport from $\mathrm{Q}_{\mathrm{A}}$ to $\mathrm{Q}_{\mathrm{B}}\left[\right.$ normalized $\left(\psi_{E T 2 o} /\left(1-\psi_{E T 20}\right)\right]$ and from $Q_{B}$ until PSI acceptors [normalized $\left(\delta_{R E 10} /\left(1-\delta_{R E 10}\right)\right.$ ]. Conversely, a reversal order of the salinity effect along the path occurred on DAT 167, which indicated a higher stress sensitivity of PSII than PSI in the long term. These results are in accord with data obtained in plants under Ca-deficiency conditions [30].

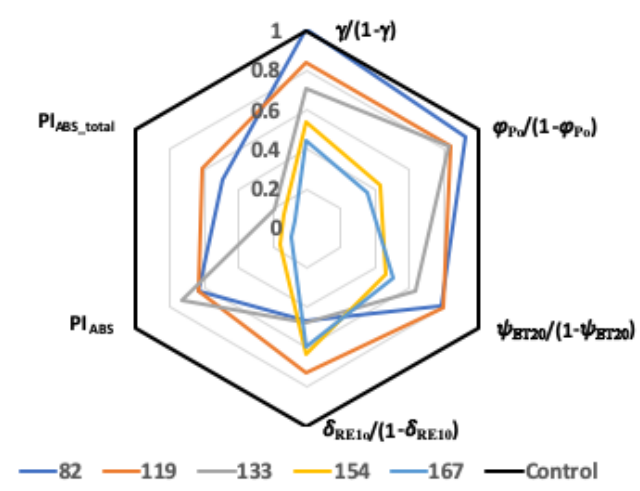

(a)

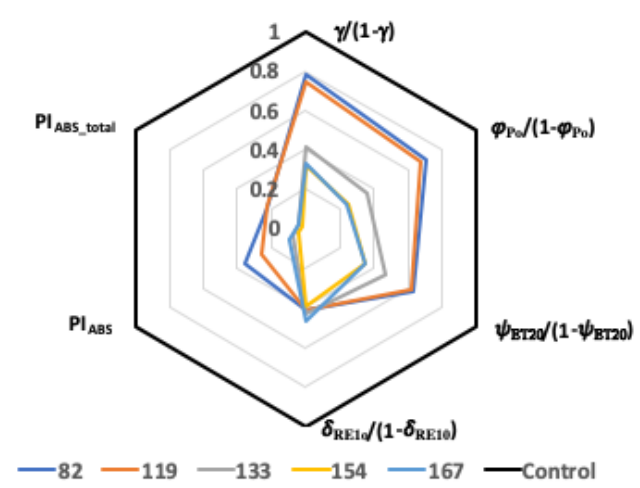

(b)

Figure 4. Spider plots of $\mathrm{PI}_{\mathrm{ABS}}, \mathrm{PI}_{\mathrm{ABS} \_t o t a l}$, and their components $\mathrm{RC} / \mathrm{ABS}=\gamma_{\mathrm{RC} 2} /\left(1-\gamma_{\mathrm{RC} 2}\right), \varphi_{\mathrm{Po}} /\left(1-\varphi_{\mathrm{Po}}\right)$, $\left(\psi_{E T 2 o} /\left(1-\psi_{E T 2 o}\right)\right.$ and $\left(\delta_{R E 1 o} /\left(1-\delta_{R E 1 o}\right)\right.$ in QA (a) and CG (b) from DAT 82 to DAT 167. Values are shown as the ratio S120/S0. The thicker line indicates the relative value $(=1)$ for the control plants (S0).

Interestingly, conversely to the other three PI-component parameters, the detrimental effect of salinity on $\delta_{R E 10} /\left(1-\delta_{R E 10}\right)$ decreased in the late of the trial (the normalized parameter increased), namely in the cultivar QA. The normalized value on DAT 167 was even higher than on DAT 82. Such a recovery of salt stress effect was not sufficient to significantly alleviate the strong effect on $\mathrm{PI}_{\mathrm{ABStot}}$. A decrease in $\delta_{R E 10}$ can be due to a reduced I-P phase $\left(1-\mathrm{V}_{\mathrm{I}}\right)$ associated to impairment of PSI content or its functioning in the linear electron flow [30]. The recovery was possibly due to the photoprotection effect of the qI mechanisms exerted through the inactivation of PSII reaction centers [53]. Increased photorespiration or increased efficiency of cyclic electron flow around PSI [60,61] may also promote non-photochemical dissipation of energy [62]. Salt stress can reduce stomatal conductance; thus, leaf temperature increases and internal $\mathrm{CO}_{2}$ concentration decreases. The latter two effects of salinity enhance RuBisCO oxygenation [63], which irreversibly produce the dangerous hydrogen as reported for the moderately salt-tolerant sugar beet [51]. The protective role of photorespiration is controversial, but it was an important mechanism that avoided photoinhibition in castor bean under salinity [64]. A decrease in PSII electron transport and the increase in non-photochemical quenching associated with alternative electron sinks (i.e., photorespiration and water-water cycle) and cyclic electron flow around PSI was proposed by [62] and recently hypothesized in rice plants under various abiotic stress [18]. However, photorespiration and water-water cycle were negligible at low temperature in grapevine leaves, which showed no photoinactivation of PSII due to a highly efficient thermal dissipation [65]. The authors underlined the necessity to measure the relative contribution of photoprotective mechanisms that avoid/limit inactivation of 
PSII, namely, $\triangle \mathrm{pH}$ and xanthophyll-dependent NPQ, photorespiration, water-water cycle (Mehler reactions), D1 repair, and PSI inactivation. Thus, additional investigations would be advisable to further undercover differences in the various photoprotective mechanisms between the two sweet pepper genotypes. The differences between the two genotypes in the salt stress response of the four partial performances along the trial reflected those of PIs as the cultivar QA was less affected than the landrace CG.

\subsection{Membrane and Leaf Models of Energy Fluxes}

The software Biolyzer provided graphical representations of the energy fluxes (pipelines) expressed per active reaction centers RC (specific/membrane model) or per measured area of leaf sample, called excited cross section $\mathrm{CS}_{\mathrm{M}}$, approximated by $\mathrm{F}_{\mathrm{M}}$ (phenomenologi$\mathrm{cal} /$ leaf model). Exposure to long-term salt stress markedly increased in S120 compared with S0 the specific fluxes of (i) the light energy absorption (ABS/RC), (ii) the trapped excitation energy (TRo/RC), and (iii) the dissipation energy (DIo/RC) (Figure 5).
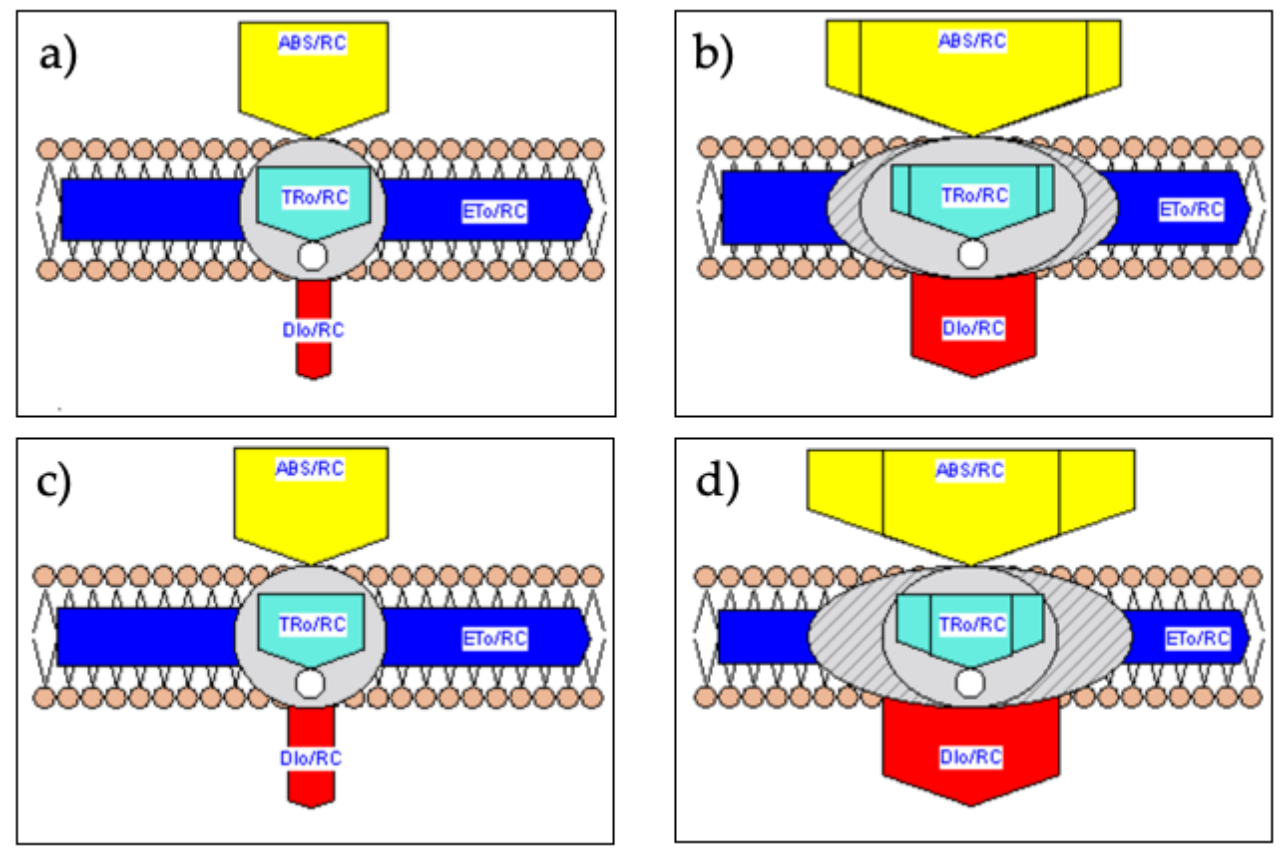

Figure 5. Pipeline models of energy fluxes per active reaction center (membrane/specific model) for S0 (panels a, c) or S120 (panels $\mathbf{b}, \mathbf{d}$ ) of QA (panels $\mathbf{a}, \mathbf{b}$ ) or CG (panels $\mathbf{c}, \mathbf{d}$ ). Each energy flux is depicted as an arrow, whose width is proportional to the relative flux. The lateral area in the $A B S / R C$ and $T R o / C S_{M}$ represents the energy fluxes related to non- $Q_{A}$ reducing centers (inactive or silent RC). The software Biolyzer produced the pipelines from the average transient curve of 24 replicates measured on DAT 167.

$\mathrm{ABS} / \mathrm{RC}$ is a relative measure of the size of antenna that supplies excitation energy to each active reaction center and is here assesses as $\left(\mathrm{M}_{\mathrm{o}} / \mathrm{V}_{\mathrm{J}}\right) / \varphi_{\mathrm{Po}}$, where $\mathrm{M}_{\mathrm{o}}$ is the approximate initial slope of $V_{t}$ curve [11]. The pipeline models also indicated that the increase in energy fluxes in S120 plants was associated with the conversion of (active) $\mathrm{RC}$ to $\mathrm{RC}_{\text {silent }}$. Inactivated reaction centers cannot reduce the primary acceptor $Q_{A}$ and do not emit a significant fluorescence amount. They significantly quench fluorescence by competitive heat dissipation of the excitation energy (heat sink centers) [15,45]. RC inactivation also occurred under drought or heat stress [66], salt stress [24,48], and nutrition stress [30]. Inactivation of RC denotes photooxidative damages to protein D1 and/or the manganese cluster of OEC [54]. Compared to the total reaction centers per cross section, the leaf models quantified $22 \%$ in QA (Figure $6 a$ ) and $45 \%$ in CG (Figure $6 \mathrm{~b}$ ) of $\mathrm{RC}_{\text {silent }}$. 

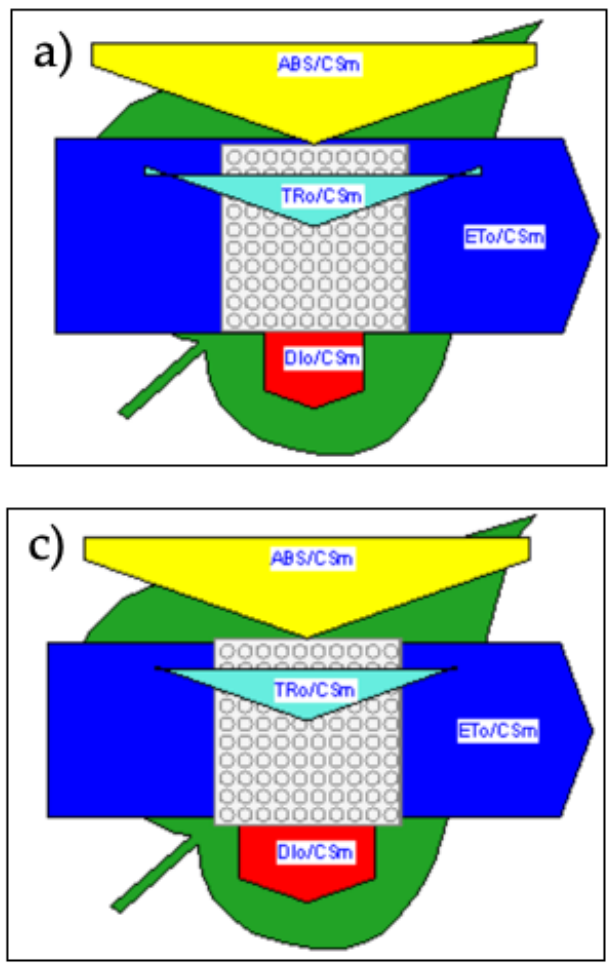
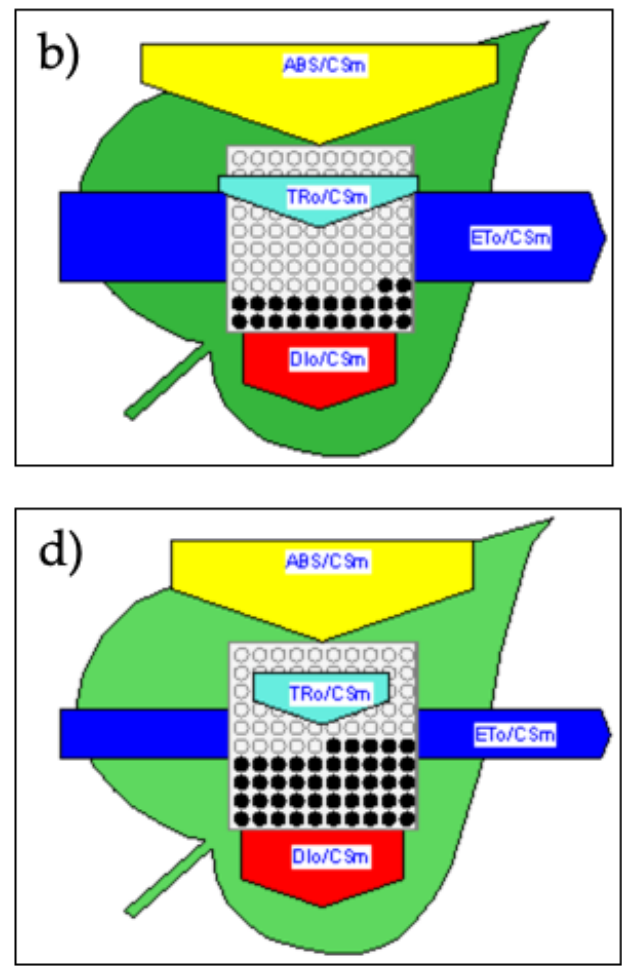

Figure 6. Pipeline models of energy fluxes per excited cross section $\left(\mathrm{CS}_{\mathrm{M}}\right)$ of leaf sample, (phenomenological/leaf model) for S0 (panels a, c) or S120 (panels b, d) of QA (panels a, b) or CG (panels c, d). Each energy flux is depicted as an arrow, whose width is proportional to the relative flux. The deepness of the green color shows chlorophyll concentration per unit leaf surface. The number of active and silent reaction centers is given by the number of white and black circles, respectively. The software Biolyzer produced the pipelines from the average transient curve of 24 replicates measured on DAT 167.

Conversely to ABS/RC, TRo/RC, and DIo/RC, a minor effect of salinity occurred to the specific electron transport ETo/RC (Figure 5). However, the protection mechanism arose at the expense of useful trapping and thus at the expense of energy delivery into the electron transport chain per excited cross section $\left(E T o / C S_{M}\right)$ (Figure 6). Reduction of $\mathrm{ETo} / \mathrm{CS}_{\mathrm{M}}$ also happened in salt-stressed sweet sorghum [25] and wheat [48], drought- or heat-stressed wheat [66], and senescing flag leaves of rice [49]. Increased heat dissipation and higher number of $\mathrm{RC}_{\text {silent }}$ resulted in lower electron transport flux per cross section in a less than a more salt-stress tolerant barley landrace [24]. Among six sweet sorghum genotypes, the highest salt-stress tolerant had the highest $\varphi_{\mathrm{Po}}, \mathrm{PI}_{\mathrm{ABS}}$, and $\mathrm{ETo} / \mathrm{CS}_{\mathrm{M}}$ and the lowest $V_{K} / V_{J}$ and number of inactive RC [25]. Similarly, we can consider the cultivar QA more tolerant than the landrace CG. The leaf model pipelines indicated that after long-term salinity conditions, ETo/CS $\mathrm{M}$ in S120 was halved in QA and reduced to 30\% in CG as compared to S0 (Figure 6), so it was the potential capacity of $\mathrm{CO}_{2}$ fixation. These data corroborate the reduction in yield under high salinity of $49 \%$ in the commercial cultivar and $82 \%$ in the landrace reported in a previous paper for the same experiment [40].

\subsection{Salt Stress Tolerance in Relation with $\mathrm{Na}^{+}$and $\mathrm{Cl}^{-}$Leaf Content}

Salt stress can be responsible for reduced photosynthesis, growth, and yield $[7,67,68]$. Despite the deep knowledge on the salt-stress mechanisms [69], some crucial aspects remain questioned, especially those regarding ion toxicity [70]. In some species, the effects of salt stress were more due to $\mathrm{Cl}^{-}$than $\mathrm{Na}^{+}$as found in fava bean by [71]. The authors reported that impaired photosynthetic capacity was associated with chlorophyll degradation not caused by $\mathrm{Na}+$, disrupting chloride homeostasis in the chloroplasts. We observed a significant stress effect on the chlorophyll content index (CCI) measured on DAT 85 [40]. CCI in the control plants was 13\% statistically significantly higher in CG than QA. However, 
CCI in S120 decreased by 31\% in CG as compared to the control, while no stress effect occurred in QA [40]. The green deepness of the leaf model in Figure 6 also shows that long-term salt stress caused a higher reduction in chlorophyll content of CG than QA. Mechanisms to avoid harmful $\mathrm{Cl}^{-}$leaf content can be less efficient than those related to $\mathrm{Na}^{+}$. For instance, [68] reviewed that conversely to sodium, chloride re-translocation via phloem from leaves to other organs has not been ascertained. Hence, cytoplasmic homeostasis is limited by the storage capacity of vacuoles. Therefore, leaf $\mathrm{Cl}^{-}$accumulation under long-term salinity eventually results in the loss of cytoplasmic homeostasis. Then chlorideinduced inhibition of both dark reaction enzymes and primary photochemistry impairs photosynthetic capacity. Indeed, promoting $\mathrm{Cl}^{-}$exclusion from shoots by substrate drench application of a bioactive molecule induced salt stress tolerance in basil [72]. Therefore, the worse exclusion of chloride from leaves of CG than QA did possibly cause the lower salt stress tolerance despite the better sodium stem compartmentalization [40]. Lines of emmer wheat that exerted two among the three salt tolerance mechanisms of osmotic tolerance, exclusion of $\mathrm{Na}^{+}$from leaves, and its compartmentalization in the vacuoles showed higher salt stress tolerance of growth than those lines that relied only on one mechanism [69]. Moreover, $\mathrm{Na}^{+}$exclusion and its tissue tolerance were mutually exclusive. Further investigations on the two pepper genotypes could focus on whether $\mathrm{Na}^{+}$and $\mathrm{Cl}^{-}$exclusions from leaves compensate for the possibly lower tissue tolerance or the higher tissue tolerance counteracts the lower exclusion. Salt acclimation by a pre-treatment a moderately low saline concentration ameliorated tolerance in maize and wheat, as shown by better water and ionic relations, less sodium accumulation and hydrogen peroxide production, and increased enzymatic antioxidants [73]. Thus, this practice could be advisable for salt-stress sensitive sweet pepper genotypes grown in soilless systems.

\section{Conclusions}

JIP test analysis of OKJIP curves demonstrated the more extended functionality of photosystems under long-term salt stress in the commercial cultivar "Quadrato d'Asti" compared to the landrace "Cazzone Giallo", which was ascribed to the lower chloride leaf content. Along the trial, the detrimental effects of salinity on the oxygen-evolving complex, the light energy absorption, the trapping of excitons, and the electron transport occurred both earlier and with a greater extent in the landrace than in the commercial cultivar. As expected, the maximum quantum yield of primary PSII photochemistry was less sensitive than the performance indexes. JIP test analysis also indicated double inactivation of PSII reaction centers in the landrace than in the commercial cultivar, with associated higher heat dissipation of excitation energy excess, which limits photodamage. The trade-off of heat dissipation was an impaired energy delivery per sample leaf area and thus impaired potential carbon fixation and yield. A recovery of the electron transport efficiency in the path from the secondary PSII acceptor until PSI acceptors occurred late in the trial. This study can provide valuable information to breeding programs, aiming to select the genes underlying the long-term salt stress tolerance.

\section{Materials and Methods}

\subsection{Plant Material, Growth Conditions, and Salt Treatments}

Two sweet pepper genotypes, the Italian widespread commercial cultivar Quadrato D'Asti (QA) and the landrace Cazzone Giallo (CG) were tested for salt stress tolerance. The experiment was carried out in a greenhouse of CREA-OF (Pontecagnano, SA, Italy) with an automatic computer-controlled soilless system equipped with a drip fertigation device. A basic nutrient solution (NS) was used to grow plants of the control (S0), while the treatment $\mathrm{S} 120$ was grown with NS supplemented with $120 \mathrm{mmol} \mathrm{NaCl} \mathrm{liter}^{-1}$ (treatment S120). The composition of NS was $(\mathrm{mN}): \mathrm{Na}^{+}, 0.2 ; \mathrm{N}^{-} \mathrm{NH}_{4}{ }^{+}, 0.5 ; \mathrm{K}^{+}, 5.0 ; \mathrm{Ca}^{2+}, 10.8 ; \mathrm{Mg}^{2+}, 4.0 ; \mathrm{Cl}^{-}$, $0.5 ;{\mathrm{N}-\mathrm{NO}_{3}}^{-}, 14.6 ; \mathrm{P}^{-} \mathrm{H}_{2} \mathrm{PO}_{4}{ }^{-}, 1.2 ; \mathrm{S}-\mathrm{SO}_{4}{ }^{-}, 3.5 ; \mathrm{HCO}_{3}{ }^{-}, 0.5$. Micronutrients were added according to [74]. The electrical conductivity $\left(\mathrm{EC}_{\mathrm{W}}\right)$ of the two nutrient solutions was 2.6 for $\mathrm{S} 0$ and $15.6 \mathrm{dS} \mathrm{m}^{-1}$ for S120. Addition of nitric acid kept the $\mathrm{pH}$ within the 5.5-6.0 range, 
while addition of fresh water stabilized the $\mathrm{EC}_{\mathrm{w}}$ of the nutrient solutions. SAIS S.p.A. (Cesena, Italy) and Cooperativa Arca 2010 (Acerra, NA, Italy) provided QA and CG seeds, respectively. Seeds were germinated in a greenhouse at Arca 2010 and transplanted one seedling per pot into a greenhouse 37 days later. Thirty pots per genotype were distributed in the two saline treatments ( 15 plants per treatment). The salt treatment started 13 days after transplanting (DAT 13) and continued until the yellow fruit stage (DAT 168). The two solutions were pumped each from an independent tank to the corresponding channel and supplied to plants by two emitters per plot (emitter flow rate: $2 \mathrm{~L} \mathrm{~h}^{-1}$ ). More details on plant growth, NS composition, its supply to and daily consumption by plants, drainage from pots, and recirculation to keep a stable NS concentration in the soilless closed system are reported in [40].

\subsection{Fast Chlorophyll a Fluorescence Transient and JIP Test}

The performances of the structure and function of the photosynthetic apparatus were assessed through the JIP test analysis of the OKJIP fluorescent transients. The measurements were carried out on dark-adapted leaves using a continuous excitation Handy PEA fluorometer (Hansatech Instruments, King-s Lynn, UK). For fluorescence induction, the instrument adopts an excitation light pulse emitted by three (red) $650 \mathrm{~nm}$ light diodes, with NIR short pass cut-off filters and a $22 \mathrm{~nm}$ spectral-line half width. Light was applied for $1 \mathrm{~s}$ at the maximum available PPFD of $3500 \mu \mathrm{mol}$ (photons) $\mathrm{m}^{-2} \mathrm{~s}^{-1}$ focused on a spot of $5 \mathrm{~mm}$ diameter. The fluorescence detector is a high-performance Pin photodiode and associated amplifier circuit. It has a peak wavelength at $650 \mathrm{~nm}$ and a spectral line half-width of $22 \mathrm{~nm}$ (Hansatech, pers. comm. 13 April 2021) The hardware is capable of detecting fluorescence at a 12-bit resolution. The Ft measurement rate was every $0.01 \mathrm{~ms}$ until $0.3 \mathrm{~ms}$ from starting of illumination, every $0.1 \mathrm{~ms}$ until $3 \mathrm{~ms}$, every ms until $30 \mathrm{~ms}$, every $10 \mathrm{~ms}$ until $300 \mathrm{~ms}$, and every $100 \mathrm{~ms}$ until $1 \mathrm{~s}$. Leaves were adapted to dark for $30 \mathrm{~min}$ using the equipped white leaf clips before assessing the OKJIP curve. Data were downloaded from the instrument to a PC using the Hansatech Pea Plus software ver. 1.01. The $F_{t}$ curve raw data were then exported and processed for JIP test analysis by the software Biolyzer HP3 ver. 3.06, developed and kindly provided to us by Prof. Reto J. Strasser (Bioenergetics Laboratory, University of Geneva, Switzerland). Table 1 reports the main technical data and the JIP test parameters with the related equations. Measurements were taken on two leaves per plant in 12 plant replicates per genotype in the morning (10:00-12:00) of 5 days spaced from DAT 82 to DAT 167.

\subsection{Statistical Analysis}

Kruskal-Wallis test by ranks was carried out on the parameters $\mathrm{V}_{\mathrm{K}} / \mathrm{V}_{\mathrm{J}}, \varphi_{\mathrm{Po}}, \mathrm{PI}_{\mathrm{ABS}}$, $\mathrm{PI}_{\mathrm{ABS} \_\mathrm{Tot}}$, to evaluate the genotype $x$ salinity $(\mathrm{G} \times \mathrm{S})$ interaction effects by comparing the mean rank of the four $\mathrm{G} \times \mathrm{S}$ combinations (CG-S0, CG-S120, QA-S0, and QA-S120). When Kruskal-Wallis tests found significant differences, a pairwise Dunn test with Bonferroni corrections was executed using Xlstat 2020 [75].

Supplementary Materials: The following are available online at https://www.mdpi.com/article/ 10.3390/plants10050887/s1, Figure S1: Fluorescence emission (r. u.) of $F_{0}, F_{K}, F_{J}, F_{I}$ and $F_{M}$ (mean \pm standard error) on (a) DAT 82 and (b) DAT 167.

Author Contributions: Conceptualization, P.G.; formal analysis, P.G.; funding acquisition, P.G.; investigation, P.G.; methodology, P.G.; visualization, P.G.; writing —original draft preparation, P.G.; writing - review and editing, P.G.; statistical analysis, M.H.S. All authors have read and agreed to the published version of the manuscript.

Funding: This research was funded by the Italian Ministry of Education, University and Research (MIUR), project GenHORT, grant number PON02-00395-3215002. 
Acknowledgments: The authors thank Marco Oliva (CNR-ISAFOM, Ecolano, Naples-Italy) and Martina Caramante (CREA-OF, Pontecagnano, Salerno-Italy) for carrying out the fluorescence measurements, Patrizia Spigno and Riccardo Riccardi (Cooperativa "Arca 2010") for growing the siblings, and Accursio Venezia (CREA-OF) for growing the plants in the soilless system in the greenhouse.

Conflicts of Interest: The authors declare no conflict of interest. The funders had no role in the design of the study; in the collection, analyses, or interpretation of data; in the writing of the manuscript; or in the decision to publish the results.

\section{References}

1. Duro, J.A.; Lauk, C.; Kastner, T.; Erb, K.-H.; Haberl, H. Global Inequalities in Food Consumption, Cropland Demand and Land-Use Efficiency: A Decomposition Analysis. Glob. Environ. Chang. 2020, 64, 102124. [CrossRef]

2. Litalien, A.; Zeeb, B. Curing the Earth: A Review of Anthropogenic Soil Salinization and Plant-Based Strategies for Sustainable Mitigation. Sci. Total Environ. 2020, 698, 134235. [CrossRef]

3. Zeven, A.C. Landraces: A Review of Definitions and Classifications. Euphytica 1998, 104, 127-139. [CrossRef]

4. Fita, A.; Rodríguez-Burruezo, A.; Boscaiu, M.; Prohens, J.; Vicente, O. Breeding and Domesticating Crops Adapted to Drought and Salinity: A New Paradigm for Increasing Food Production. Front. Plant Sci. 2015, 6. [CrossRef]

5. Razzaque, S.; Elias, S.M.; Haque, T.; Biswas, S.; Jewel, G.M.N.A.; Rahman, S.; Weng, X.; Ismail, A.M.; Walia, H.; Juenger, T.E.; et al. Gene Expression Analysis Associated with Salt Stress in a Reciprocally Crossed Rice Population. Sci. Rep. 2019, 9, 8249. [CrossRef]

6. Munns, R.; Passioura, J.B.; Colmer, T.D.; Byrt, C.S. Osmotic Adjustment and Energy Limitations to Plant Growth in Saline Soil. New Phytol. 2020, 225, 1091-1096. [CrossRef]

7. Chaves, M.M.; Flexas, J.; Pinheiro, C. Photosynthesis under Drought and Salt Stress: Regulation Mechanisms from Whole Plant to Cell. Ann. Bot. 2009, 103, 551-560. [CrossRef] [PubMed]

8. Liang, W.; Ma, X.; Wan, P.; Liu, L. Plant Salt-Tolerance Mechanism: A Review. Biochem. Biophys. Res. Commun. 2018, 495, $286-291$. [CrossRef]

9. Van Zelm, E.; Zhang, Y.; Testerink, C. Salt Tolerance Mechanisms of Plants. Annu. Rev. Plant Biol. 2020, 71, 403-433. [CrossRef]

10. Kalaji, H.M.; Jajoo, A.; Oukarroum, A.; Brestic, M.; Zivcak, M.; Samborska, I.A.; Cetner, M.D.; Łukasik, I.; Goltsev, V.; Ladle, R.J.; et al. The Use of Chlorophyll Fluorescence Kinetics Analysis to Study the Performance of Photosynthetic Machinery in Plants. In Emerging Technologies and Management of Crop Stress Tolerance; Elsevier: Amsterdam, The Netherlands, 2014; pp. 347-384. ISBN 978-0-12-800875-1.

11. Stirbet, A. On the Relation between the Kautsky Effect (Chlorophyll a Fluorescence Induction) and Photosystem II: Basics and Applications of the OJIP Fluorescence Transient. J. Photochem. Photobiol. B 2011, 104, 236-257. [CrossRef]

12. Strasser, B.; Strasser, R. Measuring Fast Fluorescence Transients to Address Environmental Questions: The JIP-Test. Photosynth. Light Biosph. 1995, 5, 977-980.

13. Guissé, B.; Srivastava, A.; Strasser, R.J. The Polyphasic Rise of the Chlorophyll A Fluorescence (O-K-J-I-P) in Heat-Stressed Leaves. Arch. Sci. 1995, 48, 147-160. [CrossRef]

14. Strasser, B.J. Donor Side Capacity of Photosystem II Probed by Chlorophyll a Fluorescence Transients. Photosynth. Res. 1997, 52, 147-155. [CrossRef]

15. Strasser, R.J.; Tsimilli-Michael, M.; Srivastava, A. Analysis of the Chlorophyll a Fluorescence Transient. In Chlorophyll a Fluorescence; Papageorgiou, G.C., Govindjee, Eds.; Advances in Photosynthesis and Respiration; Springer: Dordrecht, The Netherlands, 2004; Volume 19, pp. 321-362. ISBN 978-1-4020-3217-2.

16. Schansker, G.; Tóth, S.Z.; Strasser, R.J. Methylviologen and Dibromothymoquinone Treatments of Pea Leaves Reveal the Role of Photosystem I in the Chl a Fluorescence Rise OJIP. Biochim. Biophys. Acta BBA Bioenerg. 2005, 1706, 250-261. [CrossRef]

17. Kalaji, H.M.; Rastogi, A.; Zivcak, M.; Brestic, M.; Daszkowska-Golec, A.; Sitko, K.; Alsharafa, K.Y.; Lotfi, R.; Stypinski, P.; Samborska, I.A.; et al. Prompt Chlorophyll Fluorescence as a Tool for Crop Phenotyping: An Example of Barley Landraces Exposed to Various Abiotic Stress Factors. Photosynthetica 2018, 56, 953-961. [CrossRef]

18. Faseela, P.; Sinisha, A.; Brestič, M.; Puthur, J. Chlorophyll a Fluorescence Parameters as Indicators of a Particular Abiotic Stress in Rice. Photosynthetica 2019, 57, 108-115.

19. Brestic, M.; Zivcak, M.; Kalaji, H.M.; Carpentier, R.; Allakhverdiev, S.I. Photosystem II Thermostability in Situ: Environmentally Induced Acclimation and Genotype-Specific Reactions in Triticum Aestivum L. Plant Physiol. Biochem. 2012, 57, 93-105. [CrossRef]

20. Oukarroum, A.; Madidi, S.E.; Schansker, G.; Strasser, R.J. Probing the Responses of Barley Cultivars (Hordeum vulgare L.) by Chlorophyll a Fluorescence OLKJIP under Drought Stress and Re-Watering. Environ. Exp. Bot. 2007, 60, 438-446. [CrossRef]

21. Živčák, M.; Brestič, M.; Olšovská, K.; Slamka, P. Performance Index as a Sensitive Indicator of Water Stress in Triticum aestivum L. Plant Soil Environ. 2008, 54, 133-139. [CrossRef]

22. Zhao, J.; Lang, Y.; Zhang, S.; Zhao, Q.; Zhang, C.; Xia, J. Photosynthetic Characteristics and Chlorophyll a Fluorescence Transient in Lonicera Japonica under Drought Stress. Acta Physiol. Plant. 2019, 41, 124. [CrossRef]

23. Bano, H.; Athar, H.; Zafar, Z.U.; Kalaji, H.M.; Ashraf, M. Linking Changes in Chlorophyll A Fluorescence with Drought Stress Susceptibility in Mung Bean [Vigna Radiata (L.) Wilczek]. Physiol. Plant. 2021. [CrossRef] [PubMed] 
24. Kalaji, H.M.; Govindjee; Bosa, K.; Kościelniak, J.; Żuk-Gołaszewska, K. Effects of Salt Stress on Photosystem II Efficiency and CO 2 Assimilation of Two Syrian Barley Landraces. Environ. Exp. Bot. 2011, 73, 64-72. [CrossRef]

25. Rastogi, A.; Kovar, M.; He, X.; Zivcak, M.; Kataria, S.; Kalaji, H.M.; Skalicky, M.; Ibrahimova, U.F.; Hussain, S.; Mbarki, S.; et al. Special Issue in Honour of Prof. Reto J. Strasser-JIP-Test as a Tool to Identify Salinity Tolerance in Sweet Sorghum Genotypes. Photosynthetica 2020, 58, 518-528. [CrossRef]

26. Kalaji, H.M.; Račková, L.; Paganová, V.; Swoczyna, T.; Rusinowski, S.; Sitko, K. Can Chlorophyll-a Fluorescence Parameters Be Used as Bio-Indicators to Distinguish between Drought and Salinity Stress in Tilia Cordata Mill? Environ. Exp. Bot. 2018, 152, 149-157. [CrossRef]

27. Umar, M.; Uddin, Z.; Siddiqui, Z.S. Responses of Photosynthetic Apparatus in Sunflower Cultivars to Combined Drought and Salt Stress. Photosynthetica 2019, 57, 627-639. [CrossRef]

28. Bussotti, F.; Desotgiu, R.; Cascio, C.; Pollastrini, M.; Gravano, E.; Gerosa, G.; Marzuoli, R.; Nali, C.; Lorenzini, G.; Salvatori, E.; et al. Ozone Stress in Woody Plants Assessed with Chlorophyll a Fluorescence. A Critical Reassessment of Existing Data. Environ. Exp. Bot. 2011, 73, 19-30. [CrossRef]

29. Maliba, B.G.; Inbaraj, P.M.; Berner, J.M. The Use of OJIP Fluorescence Transients to Monitor the Effect of Elevated Ozone on Biomass of Canola Plants. Water. Air. Soil Pollut. 2019, 230, 75. [CrossRef]

30. Kalaji, H.M.; Oukarroum, A.; Alexandrov, V.; Kouzmanova, M.; Brestic, M.; Zivcak, M.; Samborska, I.A.; Cetner, M.D.; Allakhverdiev, S.I.; Goltsev, V. Identification of Nutrient Deficiency in Maize and Tomato Plants by in Vivo Chlorophyll a Fluorescence Measurements. Plant Physiol. Biochem. 2014, 81, 16-25. [CrossRef] [PubMed]

31. Swoczyna, T.; Lata, B.; Stasiak, A.; Stefaniak, J.; Latocha, P. JIP-Test in Assessing Sensitivity to Nitrogen Deficiency in Two Cultivars of Actinidia Arguta (Siebold et Zucc.) Planch. Ex Miq. Photosynthetica 2019, 57, 646-658. [CrossRef]

32. Bussotti, F.; Desotgiu, R.; Pollastrini, M.; Cascio, C. The JIP Test: A Tool to Screen the Capacity of Plant Adaptation to Climate Change. Scand. J. For. Res. 2010, 25, 43-50. [CrossRef]

33. Fratianni, F.; d'Acierno, A.; Cozzolino, A.; Spigno, P.; Riccardi, R.; Raimo, F.; Pane, C.; Zaccardelli, M.; Tranchida Lombardo, V.; Tucci, M.; et al. Biochemical Characterization of Traditional Varieties of Sweet Pepper (Capsicum annuum L.) of the Campania Region, Southern Italy. Antioxidants 2020, 9, 556. [CrossRef]

34. Rameshwaran, P.; Tepe, A.; Yazar, A.; Ragab, R. Effects of Drip-Irrigation Regimes with Saline Water on Pepper Productivity and Soil Salinity under Greenhouse Conditions. Sci. Hortic. 2016, 199, 114-123. [CrossRef]

35. Kaya, C.; Ashraf, M.; Alyemeni, M.N.; Ahmad, P. The Role of Endogenous Nitric Oxide in Salicylic Acid-Induced up-Regulation of Ascorbate-Glutathione Cycle Involved in Salinity Tolerance of Pepper (Capsicum annuum L.) Plants. Plant Physiol. Biochem. 2020, 147, 10-20.

36. Sonneveld, C.; Van der Burg, A. Sodium Chloride Salinity in Fruit Vegetable Crops in Soilless Culture. NJAS Wagening. J. Life Sci. 1991, 39, 115-122.

37. Chartzoulakis, K.; Klapaki, G. Response of Two Greenhouse Pepper Hybrids to NaCl Salinity during Different Growth Stages. Sci. Hortic. 2000, 86, 247-260. [CrossRef]

38. Aktas, H.; Abak, K.; Cakmak, I. Genotypic Variation in the Response of Pepper to Salinity. Sci. Hortic. 2006, 110, 260-266. [CrossRef]

39. Ruggiero, A.; Landi, S.; Punzo, P.; Possenti, M.; Van Oosten, M.J.; Costa, A.; Morelli, G.; Maggio, A.; Grillo, S.; Batelli, G. Salinity and ABA Seed Responses in Pepper: Expression and Interaction of ABA Core Signaling Components. Front. Plant Sci. 2019, 10, 304. [CrossRef]

40. Giorio, P.; Cirillo, V.; Caramante, M.; Oliva, M.; Guida, G.; Venezia, A.; Grillo, S.; Maggio, A.; Albrizio, R. Physiological Basis of Salt Stress Tolerance in a Landrace and a Commercial Variety of Sweet Pepper (Capsicum annuum L.). Plants 2020, 9, 795. [CrossRef] [PubMed]

41. Demmig-Adams, B.; Adams, W.W. Photoprotection in an Ecological Context: The Remarkable Complexity of Thermal Energy Dissipation. New Phytol. 2006, 172, 11-21. [CrossRef] [PubMed]

42. Strasser, R.J. The Fo and the OJIP fluorescence rise in higher plants and algae. In Regulation of Chloroplast Biogenesis; Springer: Berlin/Heidelberg, Germany, 1992; pp. 423-426.

43. Strasserf, R.J.; Srivastava, A. Govindjee Polyphasic Chlorophyll a Fluorescence Transient in Plants and Cyanobacteria. Photochem. Photobiol. 1995, 61, 32-42. [CrossRef]

44. Duysens, L. Mechanism of the Two Photochemical Reactions in Algae as Studied by Means of Fluorescence. In Studies on Microalgae and Photosynthetic Bacteria; Special Issue of Plant and Cell Physiology; Japanese Society of Plant Physiologists, University of Tokyo: Tokyo, Japan, 1963; pp. 353-372.

45. Goltsev, V.N.; Kalaji, H.M.; Paunov, M.; Bąba, W.; Horaczek, T.; Mojski, J.; Kociel, H.; Allakhverdiev, S.I. Variable Chlorophyll Fluorescence and Its Use for Assessing Physiological Condition of Plant Photosynthetic Apparatus. Russ. J. Plant Physiol. 2016, 63, 869-893. [CrossRef]

46. Oukarroum, A.; Schansker, G.; Strasser, R.J. Drought Stress Effects on Photosystem I Content and Photosystem II Thermotolerance Analyzed Using Chl a Fluorescence Kinetics in Barley Varieties Differing in Their Drought Tolerance. Physiol. Plant. 2009, 137, 188-199. [CrossRef] 
47. Srivastava, A.; Guisse, B.; Greppin, H.; Strasser, R.J. Regulation of Antenna Structure and Electron Transport in Photosystem II of Pisum Sativum under Elevated Temperature Probed by the Fast Polyphasic Chlorophyll a Fluorescence Transient: OKJIP. Biochim. Biophys. Acta (BBA) Bioenerg. 1997, 1320, 95-106. [CrossRef]

48. Mehta, P.; Jajoo, A.; Mathur, S.; Bharti, S. Chlorophyll a Fluorescence Study Revealing Effects of High Salt Stress on Photosystem II in Wheat Leaves. Plant Physiol. Biochem. 2010, 48, 16-20. [CrossRef] [PubMed]

49. Wang, Y.W.; Xu, C.; Lv, C.F.; Wu, M.; Cai, X.J.; Liu, Z.T.; Song, X.M.; Chen, G.X.; Lv, C.G. Chlorophyll a Fluorescence Analysis of High-Yield Rice (Oryza sativa L.) LYPJ during Leaf Senescence. Photosynthetica 2016, 54, 422-429. [CrossRef]

50. Henmi, T.; Miyao, M.; Yamamoto, Y. Release and Reactive-Oxygen-Mediated Damage of the Oxygen-Evolving Complex Subunits of PSII during Photoinhibition. Plant Cell Physiol. 2004, 45, 243-250. [CrossRef] [PubMed]

51. Tahjib-UI-Arif, M.; Sohag, A.A.M.; Afrin, S.; Bashar, K.K.; Afrin, T.; Mahamud, A.; Polash, M.A.S.; Hossain, M.; Sohel, M.; Taher, A. Differential Response of Sugar Beet to Long-Term Mild to Severe Salinity in a Soil-Pot Culture. Agriculture 2019, 9, 223. [CrossRef]

52. Björkman, O.; Demmig, B. Photon Yield of $\mathrm{O}_{2}$ Evolution and Chlorophyll Fluorescence Characteristics at $77 \mathrm{~K}$ among Vascular Plants of Diverse Origins. Planta 1987, 170, 489-504. [CrossRef] [PubMed]

53. Malnoë, A. Photoinhibition or Photoprotection of Photosynthesis? Update on the (Newly Termed) Sustained Quenching Component QH. Environ. Exp. Bot. 2018, 154, 123-133. [CrossRef]

54. Demmig-Adams, B.; Cohu, C.M.; Muller, O.; Adams, W.W. Modulation of Photosynthetic Energy Conversion Efficiency in Nature: From Seconds to Seasons. Photosynth. Res. 2012, 113, 75-88. [CrossRef]

55. Maxwell, K.; Johnson, G.N. Chlorophyll Fluorescence-A Practical Guide. J. Exp. Bot. 2000, 51, 659-668. [CrossRef] [PubMed]

56. Digrado, A.; Bachy, A.; Mozaffar, A.; Schoon, N.; Bussotti, F.; Amelynck, C.; Dalcq, A.; Fauconnier, M.; Aubinet, M.; Heinesch, B. Long-term Measurements of Chlorophyll a Fluorescence Using the JIP-test Show That Combined Abiotic Stresses Influence the Photosynthetic Performance of the Perennial Ryegrass (Lolium perenne) in a Managed Temperate Grassland. Physiol. Plant. 2017, 161, 355-371. [CrossRef]

57. Strasser, R.J.; Srivastava, A.; Tsimilli-Michael, M. The Fluorescence Transient as a Tool to Characterize and Screen Photosynthetic Samples. In Probing Photosynthesis: Mechanisms, Regulation and Adaptation; Yunus, M., Pathre, U., Mohanty, P., Eds.; Taylor and Francis: London, UK, 2000; pp. 445-483.

58. Tsimilli-Michael, M.; Strasser, R.J. In vivo assessment of stress impact on plant's vitality: Applications in detecting and evaluating the beneficial role of mycorrhization on host plants. In Mycorrhiza; Springer: Berlin/Heidelberg, Germany, 2008 ; pp. 679-703.

59. Wang, Z.X.; Chen, L.; Ai, J.; Qin, H.Y.; Liu, Y.X.; Xu, P.L.; Jiao, Z.Q.; Zhao, Y.; Zhang, Q.T. Photosynthesis and Activity of Photosystem II in Response to Drought Stress in Amur Grape (Vitis Amurensis Rupr.). Photosynthetica 2012, 50, 189-196. [CrossRef]

60. Joliot, P.; Joliot, A. Cyclic Electron Flow in C3 Plants. Biochim. Biophys. Acta BBA Bioenerg. 2006, 1757, 362-368. [CrossRef] [PubMed]

61. Redondo-Gómez, S.; Wharmby, C.; Castillo, J.M.; Mateos-Naranjo, E.; Luque, C.J.; de Cires, A.; Luque, T.; Davy, A.J.; Enrique Figueroa, M. Growth and Photosynthetic Responses to Salinity in an Extreme Halophyte, Sarcocornia Fruticosa. Physiol. Plant. 2006, 128, 116-124. [CrossRef]

62. Zivcak, M.; Brestic, M.; Balatova, Z.; Drevenakova, P.; Olsovska, K.; Kalaji, H.M.; Yang, X.; Allakhverdiev, S.I. Photosynthetic Electron Transport and Specific Photoprotective Responses in Wheat Leaves under Drought Stress. Photosynth. Res. 2013, 117, 529-546. [CrossRef]

63. South, P.F.; Cavanagh, A.P.; Lopez-Calcagno, P.E.; Raines, C.A.; Ort, D.R. Optimizing Photorespiration for Improved Crop Productivity. J. Integr. Plant Biol. 2018, 60, 1217-1230. [CrossRef]

64. Ziotti, A.B.; Silva, B.P.; Neto, M.C.L. Photorespiration Is Crucial for Salinity Acclimation in Castor Bean. Environ. Exp. Bot. 2019, 167, 103845. [CrossRef]

65. Hendrickson, L.; Förster, B.; Furbank, R.T.; Chow, W.S. Processes Contributing to Photoprotection of Grapevine Leaves Illuminated at Low Temperature. Physiol. Plant. 2004, 121, 272-281. [CrossRef]

66. Brestic, M.; Zivcak, M. PSII fluorescence techniques for measurement of drought and high temperature stress signal in crop plants: Protocols and applications. In Molecular Stress Physiology of Plants; Springer: Berlin/Heidelberg, Germany, 2013 ; pp. 87-131.

67. Jajoo, A. Changes in photosystem II in response to salt stress. In Ecophysiology and Responses of Plants under Salt Stress; Springer: Berlin/Heidelberg, Germany, 2013; pp. 149-168.

68. Geilfus, C.-M. Chloride: From Nutrient to Toxicant. Plant Cell Physiol. 2018, 59, 877-886. [CrossRef]

69. Rajendran, K.; Tester, M.; Roy, S.J. Quantifying the Three Main Components of Salinity Tolerance in Cereals. Plant Cell Environ. 2009, 32, 237-249. [CrossRef]

70. Isayenkov, S.V.; Maathuis, F.J.M. Plant Salinity Stress: Many Unanswered Questions Remain. Front. Plant Sci. 2019, 10, 80. [CrossRef] [PubMed]

71. Tavakkoli, E.; Rengasamy, P.; McDonald, G.K. High Concentrations of Na+ and Cl- Ions in Soil Solution Have Simultaneous Detrimental Effects on Growth of Faba Bean under Salinity Stress. J. Exp. Bot. 2010, 61, 4449-4459. [CrossRef]

72. Carillo, P.; Woodrow, P.; Raimondi, G.; El-Nakhel, C.; Pannico, A.; Kyriacou, M.C.; Colla, G.; Mori, M.; Giordano, M.; De Pascale, S.; et al. Omeprazole Promotes Chloride Exclusion and Induces Salt Tolerance in Greenhouse Basil. Agronomy 2019, 9, 355. [CrossRef] 
73. Zuo, Z.; Ye, F.; Wang, Z.; Li, S.; Li, H.; Guo, J.; Mao, H.; Zhu, X.; Li, X. Salt Acclimation Induced Salt Tolerance in Wild-Type and Chlorophyl b-Deficient Mutant Wheat. Plant Soil Environ. 2021, 67, 26-32. [CrossRef]

74. Hoagland, D.R.; Arnon, D.I. The Water-Culture Method for Growing Plants without Soil. Circ. Calif. Agric. Exp. Stn. 1950, $347,32$.

75. Addinsoft, A. XLSTAT Statistical and Data Analysis Solution; Long Island, NY, USA, 2019. Available online: https://www.xlstat. com/en/news/2020 (accessed on 5 November 2020). 